\title{
DOCUMENTATION AND MONITORING OF BUILT HERITAGE IN ABU DHABI, UAE
}

\author{
Salman Muhammad
}

Abu Dhabi Tourism and Culture Authority, Abu Dhabi, UAE

salman.ali@tcaabudhabi.ae

KEY WORDS: Documentation, monitoring, condition mapping, measured surveys

\begin{abstract}
:
The ancient oasis-city of Al Ain in Abu Dhabi Emirate still retains the most important and outstanding cultural heritage of United Arab Emirates (UAE). The larger area of Abu Dhabi Emirate comprised of archaeological sites, cultural landscapes and historic buildings dating back to 3rd millennium to the recent pre-oil era. Traditional materials like stone, earth and palm wood were used in combination with local construction methods. For the last seven years the newly formed Abu Dhabi Tourism \& Culture Authority (TCA Abu Dhabi) $^{1}$ has been actively involved in conservation of built heritage in Abu Dhabi Emirate with the help of its Conservation Section.
\end{abstract}

Documentation prior to any conservation and restoration works is considered as a basic pre-requisite for understanding an historic building or site. It is a process which continues during the conservation of any monument and is the only accurate tool for recording information in order to understand the structure, ultimately leading to the management of cultural heritage. Application and use of tools, ranging from basic manual techniques to 3D laser scanning, based on the best practices and international guidelines the exercise will help in establishing a documentation lab with standard procedures, specifications and tools for the documentation and monitoring the built heritage of Abu Dhabi Emirate.

This paper will discuss a range of case studies and will demonstrate how documentation and monitoring of the built heritage has augmented the various conservation initiatives on a variety of building types.

\section{INTRODUCTION}

One of the major aims of this paper is to highlight the importance of creating base records to address a variety of documentation needs while conserving the built heritage in the Abu Dhabi Emirates of UAE. This will also emphasize the approach of documentation unit of Conservation Section in applying and localizing the international guidelines and the best practices in documentation.

The nature of different heritage sites (buildings, archaeology, ruins etc.) needs a case-specific approach in creating such base records. It is also important to note that most of the records were produced for the first time to address the conservation needs in the long run. The case studies presented in the paper will showcase the approach, tools, techniques and the product in documenting various sites for study, monitoring and condition mapping purposes. These case studies were documented by using a range of simple tools and advanced tools like 3D laser scanners.

\section{DOCUMENTATION}

Documentation is related to the systematic collection and archiving of records of heritage asset in order to preserve them for future reference. Documentation also refers to the stock of existing information while recording is the active process of creating and collecting new records. (Letellier et al., 2007: 117).
The most widely accepted international document on the conservation of built heritage is Venice Charter, which also stressed on documentation as an integral part of conservation process. It says in Article 16:

"In all works of preservation, restoration or excavation, there should always be precise documentation in the form of analytical and critical reports, illustrated with drawings and photographs. Every stage of the work of clearing, consolidation, rearrangement and integration, as well as technical and formal features identified during the course of the work, should be included. This record should be placed in the archives of a public institution and made available to research workers. It is recommended that the report should be published." (ICOMOS, 1964)

In 1996, ICOMOS laid down the objectives, principles, responsibilities, and extent for recording cultural heritage which says, "Recording is the capture of information which describes the physical configuration, condition and use of monuments, groups of buildings and sites, at points in time and it is an essential part of the conservation process."

In consideration with the parameters mentioned in international charters, TCA Abu Dhabi developed a three-tiered documentation method (table 1). Each level corresponds to an increase in detail and scope and builds on the previous for providing a certain amount of information. (Salman, Chabbi, 1012).

Under UNESCO's recommendation to manage and protect the cultural heritage of the Emirate, Abu Dhabi Authority for Culture \& Heritage (ADACH) was created in 2005. In 2012, ADACH merged with Abu Dhabi Tourism Authority (ADTA) and the Cultural Division of the Tourism Development \& Investment Company (TDIC) to form Abu Dhabi Tourism and Culture Authority (TCA Abu Dhabi). 


\begin{tabular}{|c|c|c|c|}
\hline 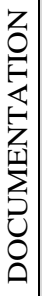 & LEVEL I & LEVEL II & LEVEL III \\
\hline 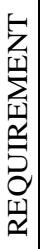 & $\begin{array}{l}\text { Searching } \\
\text { existing } \\
\text { records }\end{array}$ & $\begin{array}{l}\text { Creating new or } \\
\text { (updating) } \\
\text { existing } \\
\text { documentation }\end{array}$ & $\begin{array}{l}\text { Creating } \\
\text { additional new } \\
\text { documentation }\end{array}$ \\
\hline & \multirow{2}{*}{$\begin{array}{l}\text { Researching } \\
\text { and finding old } \\
\text { records and } \\
\text { use them as a } \\
\text { base } \\
\text { documentation }\end{array}$} & $\begin{array}{l}\text { To fulfil the } \\
\text { existing needs } \\
\text { of the } \\
\text { project/study }\end{array}$ & $\begin{array}{l}\text { To serve the } \\
\text { purpose for } \\
\text { future needs of } \\
\text { the project like } \\
\text { monitoring, } \\
\text { maintenance } \\
\text { etc. }\end{array}$ \\
\hline 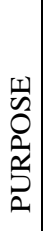 & & \multicolumn{2}{|c|}{$\begin{array}{l}\text { The absence of any old } \\
\text { records/documentation would mean } \\
\text { creating new documentation and } \\
\text { update according to special future } \\
\text { needs }\end{array}$} \\
\hline 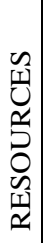 & $\begin{array}{l}\text { Old reports, } \\
\text { photographs, } \\
\text { surveys, } \\
\text { drawings etc. }\end{array}$ & $\begin{array}{l}\text { Digitization, re- } \\
\text { surveys, } \\
\text { photographs, } \\
\text { written } \\
\text { descriptions etc. }\end{array}$ & $\begin{array}{l}\text { Latest tools for } \\
\text { documentation } \\
\text { \& information } \\
\text { management }\end{array}$ \\
\hline
\end{tabular}

Table 1. Documentation methodology

\subsection{Establishing Documentation Lab}

A range of available tools, software and techniques were combined together in order to produce reliable and accurate base data based on the best practices in the field. As a start, with the available in-house capacity, simple measuring tools were used in producing the measured drawings of sites. Later a more sophisticated combination of digital SLR camera, laser disto, total station/REDM (Reflector less Electromagnetic Distance Measurement), computers with softwares like AutoCAD ${ }^{\circledR}$, TheoLT ${ }^{\circledR}$, PhotoPlan ${ }^{\circledR}$ and Photoshop ${ }^{\circledR}$ were employed in producing the measured and topographical surveys of rather regular buildings and sites. The more irregular archaeological sites were documented with the help of outsourced 3D laser scanning assignments. The base data obtained from the 3D laser scanning work was used to study the sites for various purposes.

In parallel all the collected data requires having an organized and logical structure to archive and retrieve it. It is very important that this system follows a logic common to all users for easy searching and retrieving, particularly since the
Conservation Section is split between Abu Dhabi and Al Ain and its scope of work covers the whole emirate. A comprehensive digital information management system has been established for each site to provide a structure for digital records following the conservation process and organized into folders corresponding to the different phases of study, assessment, planning and implementation (Salman, Chabbi, 2012).

\section{MONITORING}

Given the nature of the heritage sites in the Abu Dhabi Emirates, the Conservation Section has developed an approach to systematically and accurately monitor the behaviour of different building elements and interventions in order to prevent any risk to their precious and fragile fabric. Monitoring plays an important role in detecting when an abnormal change occurs and whether it changes over time, and in helping identify the causes of the problem. Monitoring may occur before deciding on a particular repair and can therefore be considered a preventive conservation measure. Monitoring before intervening can keep track of the level of threat, trigger a response, and assist in better understanding the causes of deterioration. Monitoring during and after an intervention can inform how a repair and the building itself are performing, particularly where critical defects such as severe cracks, bulges and rising damp in walls, warping roof beams, and settlements in floors and foundations were first observed.

The Conservation Section has developed a monitoring methodology to regularly keep track over a determined period of time of a building or site's defects, its environmental conditions such as rain, humidity, wind, and temperature, and the performance of interventions that have been carried out.

It is not necessary to monitor each feature or every intervention. Therefore, as a first step in elaborating the monitoring methodology, it was critical to know which different building features and intervention types needed monitoring. A list was compiled by listing these features into four main categories such as inherited building anomalies, permanent building features, short-term intervention methods to support conservation, and long-term intervention methods. This data was compiled into a matrix and paired with the appropriate tools and procedures that range from simple gypsum crack monitors and digital photography to REDM survey of laser reflective targets for tracking structural movement and erosion. A flowchart (Fig. 1) was developed based on this matrix to describe the procedure to follow with regards to visit frequency and level of threats. (Salman, Chabbi, 2012).

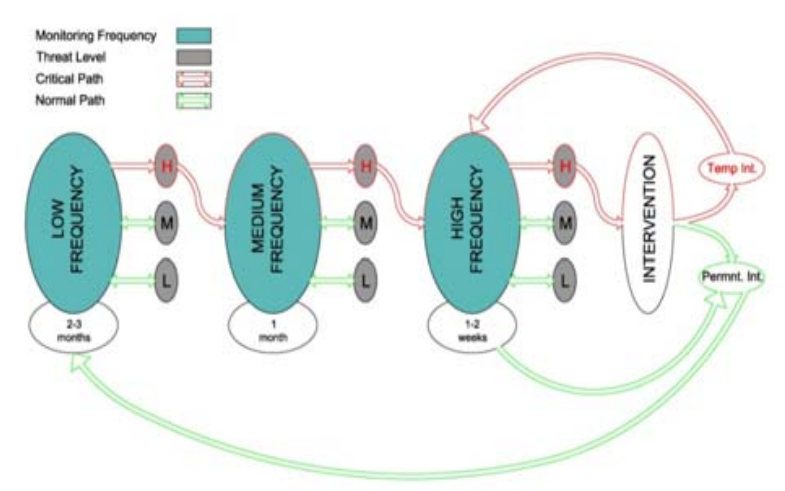

Figure 1. Monitoring flowchart 


\section{CONDITION MAPPING}

Recording and mapping the existing conditions of a heritage site is an important process in knowing the amount of any damage, causes and ultimately be useful in proposing an intervention as part of conservation. A glossary of various conditions was created and updated based on the site conditions and past surveys done by building conservation team.

As a base data various drawings and ortho-rectified elevations were produced as part of documentation. In many cases, where the updated data was not available, archival documentation was used to map the conditions on site which were later digitized. In the case of highly sensitive archaeological sites non intrusive techniques such as 3D laser scanning was employed and produced highly accurate base data in the form of contour plans, 3D model and ortho-rectified elevations.

\section{CASE STUDIES}

\subsection{Measured Surveys: Adobe Buildings Documentation Camp VERNADOC 2012, Al Ain}

5.1.1 Project Background: VERNADOC is annual international camp mostly attended by researchers, professionals, technicians and students to document the vernacular built heritage around the world using simple tools and techniques. With new developments in heritage documentation the professionals these days rely mostly on instrument-based surveys while the most basic and important rules of documentation with hands using simple tools and techniques normally get less attention and thus forgotten over time. VERNADOC is a decade old effort of preserving the art of documenting and producing the survey drawings of vernacular buildings manually.

VERNADOC camp works under the auspices of CIAV (ICOMOS) which is one of the scientific committees of ICOMOS taking care of vernacular architecture around the world. In conjunction with the CIAV annual meeting in Abu Dhabi, in November 2012, TCA Abu Dhabi organized the VERNADOC in Al Ain. Four vernacular adobe buildings were documented and exhibited the drawings at the end as part of CIAV annual congress.

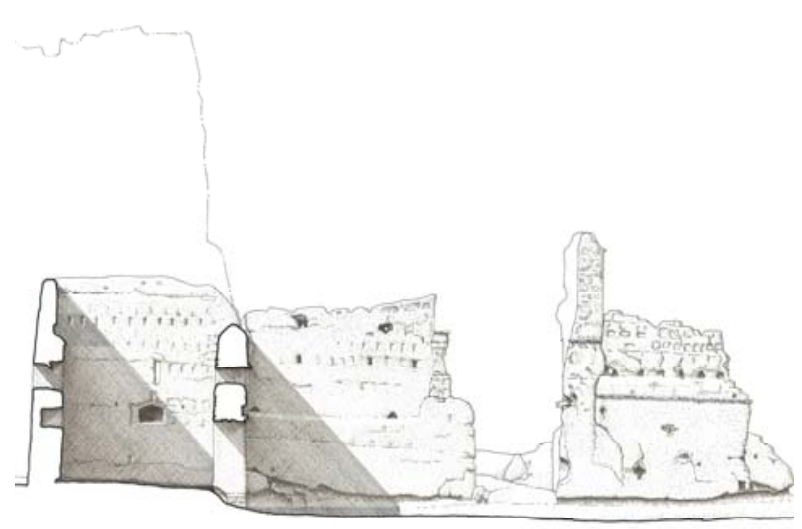

Figure 2. A sectional elevation of Bin Bidowah Tower Hosue in Al Qattara Oasis (original 1:50) produced by Finnish architect Markku Matila
5.1.2 Project Scope and Objectives: One of the main objectives of arranging this camp in $\mathrm{Al}$ Ain is to promote and showcase the architectural heritage of Abu Dhabi in particular and UAE in general to the audience around the world. With recent inclusion of the cultural sites of $\mathrm{Al}$ Ain to the UNESCO's World Heritage List (WHL), this camp provided TCA Abu Dhabi an opportunity to showcase the architectural heritage in Abu Dhabi and their efforts in conserving it.

Two weeks long camp was attended by ten international experts who worked with seven local professionals and architectural students. The camp provided an opportunity to learn by sharing their experiences with each other thus broadening the skill and knowledge base.

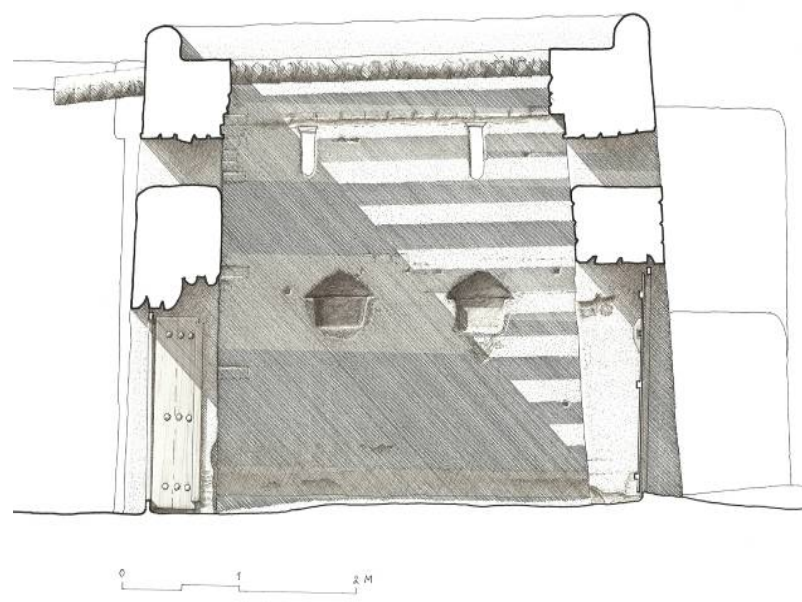

Figure 3. A sectional elevation of a room next to Qattara Souk in Al Qattara Oasis (original 1:25) produced by Finnish architect Markku Matila

5.1.3 Project Deliverables: At the end of the camp 34 hand drawn architectural drawings were produced and exhibited for general public and experts attending the CIAV annual meeting in $\mathrm{Al}$ Ain.
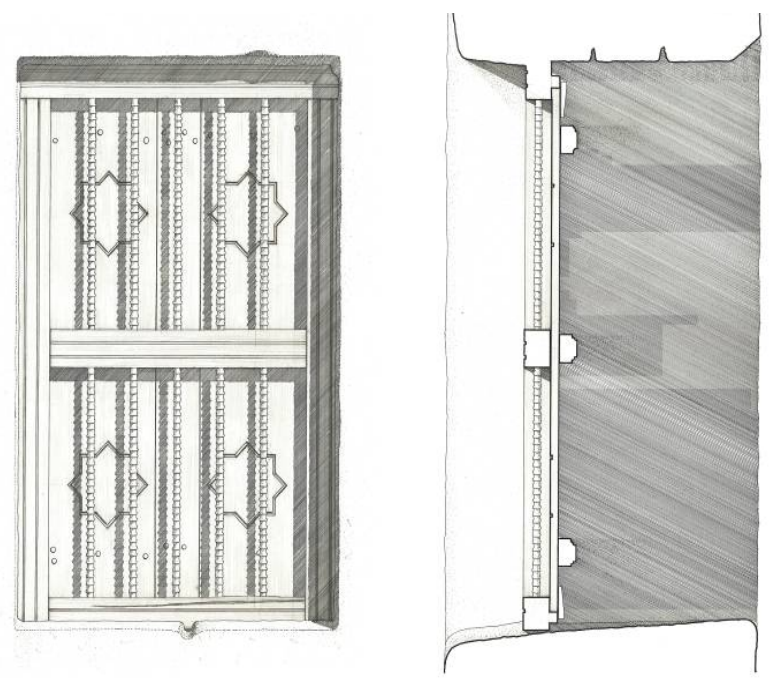

Figure 4. Detail elevation and a section of a wooden window of Mosque in Al Qattara Oasis (original 1:5) produced by the author. 


\subsection{Measured Surveys: Sheikh Mohamed Bin Khalifa House, Al Ain}

The Sheikh Mohamed Bin Khalifa House in Al Ain is one of the few surviving examples of buildings which represents the transition time of Abu Dhabi Emirates from pre-oil era to postoil era. The building was constructed in 1958 which also represents a time of transition in building technology when most of the buildings were constructed using modern construction techniques and materials. TCA Abu Dhabi has been working in developing conservation and reuse proposals for the building.
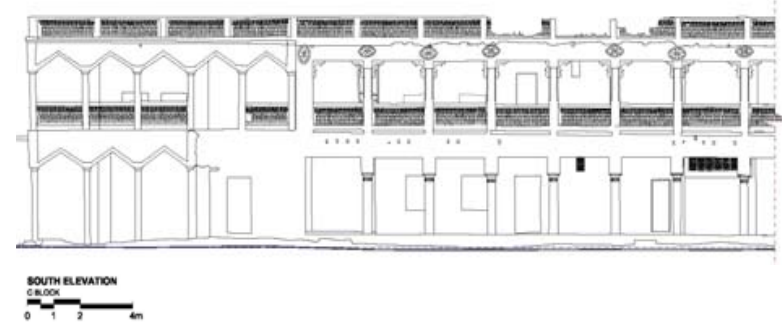

Figure 5. A Final south elevation of private block produced in AutoCAD ${ }^{\circledR}$

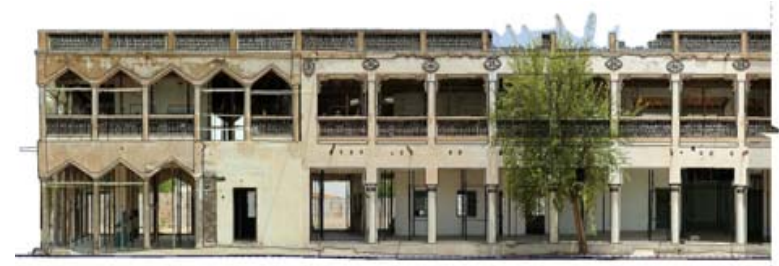

soumenevirow

Figure 6. A rectified south elevation of private block.

As part of documentation measured surveys of the building and topographical survey of the site in its as-found state is a prerequisite to conservation planning to provide the base data for conservation architects, conservators and archaeologists, and assist them in devising conservation interventions and supporting site presentation schemes. The Conservation Section has been working on producing topographical and measured building surveys (fig. 5) using instrument-based REDM technology with a total station and allied software package. Detail surface features and architectural decorations were documented with the help rectified photography (fig. 6).

\subsection{Condition Mapping: Hili 17 Archaeological Site, Al Ain}

Hili 17 is an archaeological site dating from the Iron Age (ca. $1000 \mathrm{BCE}$ ) and located in the northwest area of Hili Archaeological Park in Al Ain. Excavated in the early 1990s, most of the prominent and exposed building features have deteriorated due to their fragility and exposure to environmental factors over the past two decades. In response, the Department of Conservation initiated emergency conservation interventions to stabilize the site while long-term solutions are being planned (Marcus et al., 2012).

Archival documentation on Hili 17 included hand-drawn maps and drawings, photographs and written reports prepared during the excavation campaigns. The hand-drawn plans were digitized and used as a base to map conditions and comparatively study how the site has changed over time. A glossary and legend were developed to identify conditions on-site, such as plant growth, erosion, cracks, water pooling and water gullies, etc. These conditions were recorded by hand on the base records. Later all conditions were digitized in AutoCAD ${ }^{\circledR}$. Old photographs taken during site excavations were compared with new photographs taken from the same position to gauge the extent of lost fabric and features (Marcus et al., 2012).

Information on building features, the condition and site topography were updated using the latest non-intrusive tools. The non-linear and sculptural form of the site features were heavily eroded due to the fragile nature of the earthen material. The high significance of the site as a component of the World Heritage serial property and its deteriorated condition prompted the conservation team to use a non-contact documentation method in order to provide the highest level of detail record of the site; therefore, a 3D laser scan was therefore commissioned.

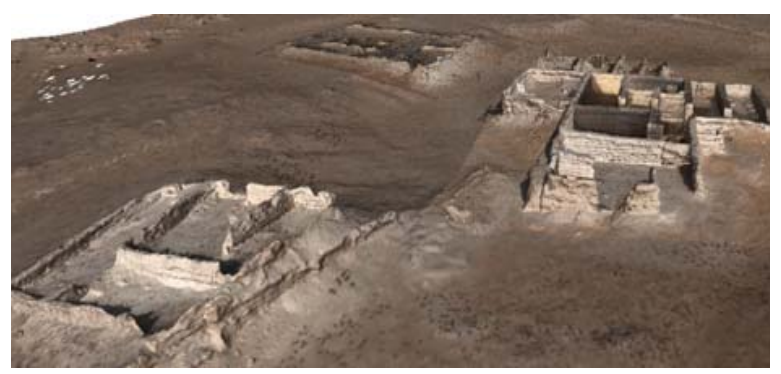

Figure 7. A snap shot of 3D model shows all three houses of Hili 17.

The main purpose was to create a digital 3D model to complement the field survey (Fig. 7). Over 100 scans at a $5 \mathrm{~mm}$ resolution and more than 3000 digital photographs were taken in four days to create the 3D model which was geo-referenced by GPS measurement. 3D model was used to extract secondary products like contours, sectional elevations, plans and the rectified (orthogonal rubber-sheeted) images of each wall elevation (Fig. 8). These plans, elevations and sections extracted were used to accurately map conditions. A detailed GIS system with additional panoramas was created as a management tool to document each wall of the site. (Salman, Chabbi, 2012).

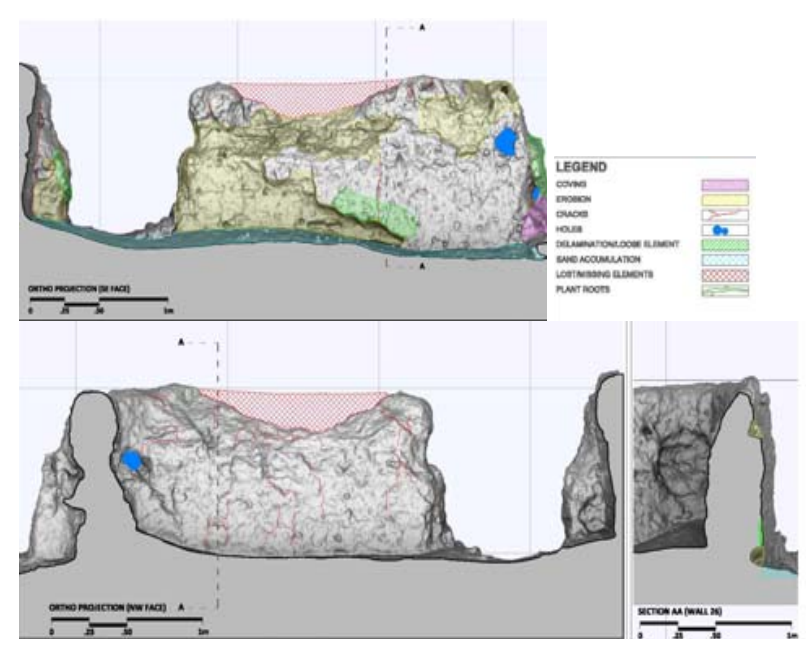

Figure 8. Using a sectional elevation extract from the laser scan to accurately map the conditions of a wall in house 1 . 


\subsection{Monitoring Structural Cracks: Om Hosn Tower, Liwa}

The site of Om Hosn is located at the western end of Liwa oasis in Abu Dhabi Emirate. Before the recent archaeological investigations and emergency conservation works the site was an assembly of collapsed stone tower and ruined walls. Constructed with local rubble stone and mortar, the layout comprises a round tower and two rectangular rooms with low walls on its north and south sides. Unlike other historic structures in Liwa, Hayla Tower is the only stone building with similar construction type resembling the typology of Om Hosn. (Salman, Ali, Benjamin, 2010)

Om Hosn is mentioned in the 1955 list (the UK and Saudi Memorials drawn up at the time of the Buraimi dispute) as being called Huwayle or Umm Hisn and as having been built by the Manasir tribe in the early years of the Qatar- Abu Dhabi war, 1883-1890. (Peter Sheehan, 2010)

The Conservation Section of TCA Abu Dhabi has carried out an exercise of identifying the threats and needs of the site in August 2010 and later implemented a monitoring system. Later in March 2013 the Conservation Section implemented the emergency conservation after monitoring the critical elements.

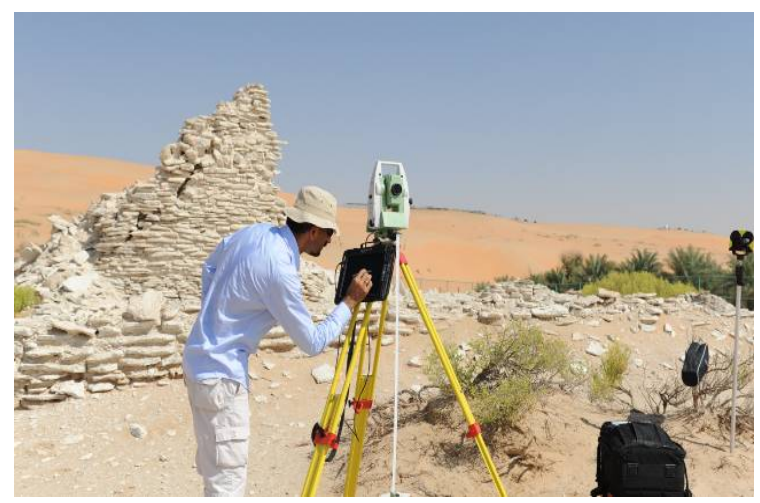

Figure 9. Monitoring survey of a major crack with total station at Om Hosn site in Liwa.

A large section of wall on the south is still intact but with a huge vertical structural crack. An instrument-based survey (REDM) with a total station was preferred due to its high accuracy and precision (Fig. 9). Four permanent reflective targets were fixed on the both sides of crack and their positions were recorded three-dimensionally with total station from a permanent benchmark on the ground. The field measurements were collected by a field computer and directly processed in real-time with a combination of softwares on site. The 3 dimensional coordinates of each target were collected during three separate surveys in one year and then analyzed (Fig. 10). Very minor movements were observed during the analysis of the targets positions. A rectified elevation of wall was produced to document the process.

In addition to the monitoring survey with Total Station a set of gypsum monitors were also installed across the crack on three locations. Since the site is very far from the field offices and not possible to monitor regularly with Total Station therefore, these simple gypsum monitors were installed to monitor visually by the craftsperson on site. A crack in the gypsum monitor indicates movement in the big crack below. The width of the crack in the gypsum monitor is measured with a special ruler called a "crack-width gauge."

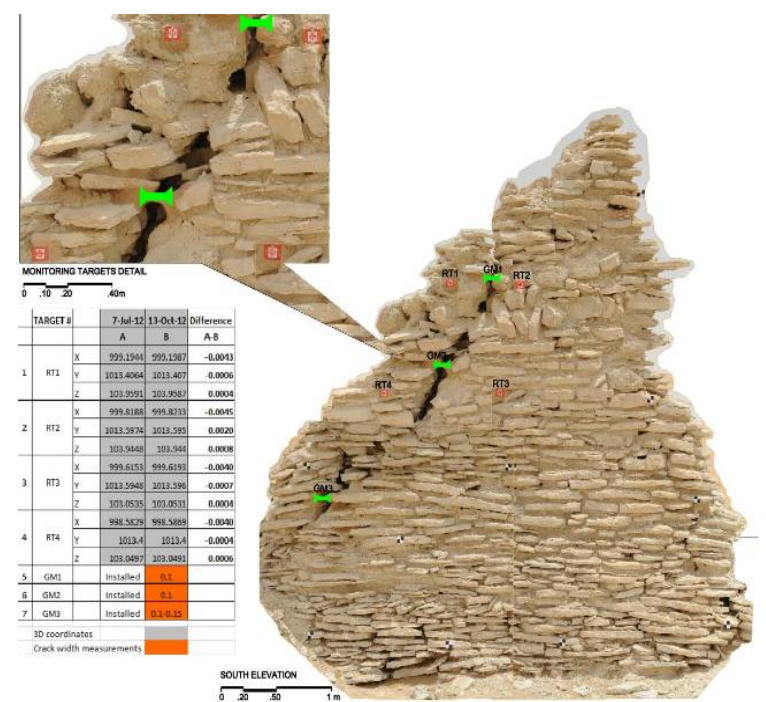

Figure 10. The rectified south elevation shows the locations of targets and gypsum monitors recorded with total station.

\section{CONCLUSION}

A variety of case studies presented in this paper illustrate the need of a systematic documentation and monitoring of heritage site in Abu Dhabi Emirates. In the past three years the Conservation Section of TCA Abu Dhabi established a practice of working on documentation and monitoring needs of sites as an integral part of the project and conservation process. The whole process and the data generated from it inform the next levels of each project thus fulfilling the major guidelines mentioned in many international charters. Various bench marks have been created in terms of generated data based on best international practice in the field. One of the main objectives for the coming years is to carry the whole process to a next and advanced level more in terms of standardizing the process, enlarging the capacities and creating a local base.

\section{REFERENCES AND SELECTED BIBLIOGRAPHY}

1. Abu Dhabi Authority for Culture \& Heritage. "Laser scanning the archaeological site of Hili 17 in Al Ain." This Month (May 2011): 40-41.

2. Al Kaabi, O., Malekabbasi, A., Muhammad, S., Aqeel, A., Codrai, J., \& Mehairibi, N. " Management Context report on The Late Sheikh Mohamed Bin Khalifa House Conservation Project. "In house report (In preparation). TCA Abu Dhabi. (June 2013).

3. Andrews, D. D., Jon Bedford, and Heather Papworth. 2009. Measured and drawn: techniques and practice for the metric survey of historic buildings. Swindon: English Heritage.

4. Andrews, D.P. et al. "Partnership in learning: English Heritage and The Raymond Lemaire International Centre for Conservation." In Proceedings of the XXIst International Symposium, CIPA 2007: antiCIPAting the future of the cultural past, edited by Andreas Georgopoulos. Athens, Greece: CIPA, 2007.

Available online:

http://cipa.icomos.org/fileadmin/template/doc/ATHE NS/FP014.pdf 
5. Barber, D. 2007. 3D Laser Scanning for Heritage: advice and guidance to users on laser scanning in archaeology and architecture. Swindon: English Heritage.

6. Bowden, Mark. 2002. With alidade and tape: graphical and plane table survey of archaeological earthworks. Swindon: English Heritage.

7. $\quad$ Eppich, Rand and Amel Chabbi, eds. 2007. Recording, documentation, and information management for the conservation of heritage places: illustrated examples. Los Angeles: Getty Conservation Institute.

8. Eppich, R. and Francois LeBlanc. "Documenting our past for the future." Getty Conservation newsletter Vol.20 No.3 (2005): 5-9. Available online: http://www.getty.edu/conservation/publications/newsl etters/20_3/feature.html.

9. English Heritage. 2000. Metric survey specifications for English Heritage. Swindon: English Heritage.

10. International Council for Monument and Sites. 1931. The Athens Charter for the Restoration of Historic Monuments (The Athens Charter). Athens Conference, 21-30 October 1931.

11. International Council for Monument and Sites. 1964. International Charter for the Conservation and Restoration of Monuments and Sites (The Venice Charter). Second International Congress of Architects and Technicians of Historic Monuments, Venice, 2531 May 1964.

12. International Council on Monuments and Sites. 1990. Guide to recording historic buildings. London: Butterworth Architecture.

13. International Council for Monument and Sites. 1996. Principles for the Recording of Monuments, Groups of Building and Sites. ICOMOS 11th General Assembly, Sofia, Bulgaria, 5-9 October 1996.

14. Letellier, Robin, Werner Schmid, and François LeBlanc. 2007. Recording, documentation, and information management for the conservation of heritage places: guiding principles. Los Angeles: Getty Conservation Institute.

15. Muhammad, S., and Chabbi. A. "Documentation and recording for the conservation of built heritage in Abu Dhabi Emirate." Paper presented at the $3^{\text {rd }}$ International Architectural Conservation Conference \& Exhibition, IACC 2012, Dubai, U.A.E., 17-19 December, 2012.

16. Marcus, B., Muhammad, S., and G. Palumbo. "Conservation and management of earthen archaeological sites in Abu Dhabi, UAE.” Paper presented at the XIth International Conference on the Study and Conservation of Earthen Architectural Heritage, Terra 2012, Lima, Peru, 22-26 April, 2012. (Publication forthcoming)

17. Menuge, Adam, Nicholas Cooper, Robert Hook, and John King. 2006. Understanding historic buildings a guide to good recording practice. Swindon: English Heritage.

18. Muhammad, S., Marcus, B., and A. Malekabbasi. "Preliminary Condition Assessment of Om Hosn." In house report. Abu Dhabi Authority for Culture \& Heritage. (November 2010).

19. Santana-Quintero, M., Blake, B., Eppich, R., Ouimet, C. "Heritage documentation for conservation: partnership in learning." In Proceedings of the 16th ICOMOS General Assembly and International
Symposium: 'Finding the spirit of place - between the tangible and the intangible', edited by Laurier Turgeon. Québec, Canada: Presses de l'Université Laval, 2008. Available online: http://www.international.icomos.org/quebec2008/cd/t oindex/77_pdf/77-1875-187.pdf

20. Sheehan., P. “ Update on progress ar Qalat Umm Hosn, Liwa, Western Region”. In house report. TCA Abu Dhabi. (April 2013).

21. RecorDIM task group 16. 2007. Draft Report on International Heritage Documentation Standards. Published online at: http://cipa.icomos.org/fileadmin/template/doc/RECO RDIM/TG16_REPORT.pdf 